\title{
A influência da ideologia patriarcal na definição dos brinquedos infantis
}

The influence of patriarchal ideology in defining children's toys Antônia Camila de Oliveira Nascimento*

Resumo - O presente artigo é parte de um trabalho monográfico, realizado na Universidade do Estado do Rio Grande do Norte (Uern). Neste estudo, levamos em consideração os determinantes materiais e ideológicos do patriarcado na definição dos brinquedos. Nesse sentido, apoiamo-nos nas categorias ideologia, patriarcado, gênero, consciência e divisão sexual do trabalho. Para a coleta de dados, utilizamos como instrumento entrevistas contendo um roteiro de perguntas semiestruturadas. Diante disto, podemos perceber que os brinquedos não são simplesmente sinônimos de brincar, mas são também representações ideológicas de uma cultura que separa homens e mulheres, atribuindo a eles papéis sociais determinados segundo o sexo.

Palavras-chave: ideologia; patriarcado; brinquedos infantis.

Abstract - This article is part of a monograph, held at the State University of Rio Grande do Norte (Uern). In this study, we considered the ideological and material determinants of patriarchy in the definition of toys. In this sense, we approached the categories: ideology, patriarchy, gender, awareness and sexual division of labor. To collect the data, we used as a tool semi-structured scripted interviews. Given this, we can conclude that toys are not only synonymous with play, but also ideological representations of a culture that separates men and women by assigning them certain social roles according to sex. Keywords: ideology; patriarchy; children's toys.

\footnotetext{
* Assistente social. Especialista em Gestão Pública pelo Instituto Federal de Educação, Ciência e Tecnologia do Rio Grande do Norte. Mestranda do Programa de Pós-Graduação em Serviço Social e Direitos Sociais da Universidade do Estado do Rio Grande do Norte (PPGSS/UERN). Correspondência: Rua Marechal Hermes, 20, Paredões, Mossoró/ RN. CEP: 59618160. Email:<camyla.oliveira25@gmail.com>
} 


\section{ApVistg all paUtg}

\} A INFLUÊNCIA DA IDEOLOGIA PATRIARCAL - NASCIMENTO, A. C. O. \}

DOI: 10.12957/REP.2016.25399

\section{Introdução}

O presente trabalho tem como objetivo analisar a expressão da ideologia patriarcal nos brinquedos infantis, levando em consideração os determinantes materiais e ideológicos nesses brinquedos, que contribuem para a cristalização dos significados dominantes sobre os gêneros (feminino e masculino). Acreditamos que os sujeitos são ideologicamente cerceados desde a infância, "treinados" desde cedo para assumirem papéis sociais de acordo com sexo. Dessa forma, as representações ideológicas dominantes presentes nos brinquedos possibilitam usos que se destinam a instituir significados para que as crianças reproduzam os papéis socialmente estabelecidos.

Enquanto a criança se apropria e usa os brinquedos disponibilizados e referendados pelos adultos, ela está acionando valores socialmente definidos como o que é masculino e feminino, ao mesmo tempo em que dramatiza as próprias vivências de gênero, ou seja, introjeta facetas de uma cultura que separa homens e mulheres, atribuindo-lhes valores sociais dominantes.

Considerando a influência dos brinquedos como fator significante na reprodução da ideologia patriarcal na infância, a presente pesquisa permitiu analisar a influência dos brinquedos nesta estruturação, tendo em vista que papéis de gênero e comportamentos estão, de forma simbólica, materializadas neles, criando valores socialmente aceitos como verdades "absolutas".

Em nossa pesquisa adotamos o materialismo histórico dialético, uma vez que ele possibilitou compreender o objeto numa relação profundamente ligada à divisão de classes e a forma particular como a classe dominante difunde suas ideias, tornando-as universais. Daí a importância desse método, posto que busca não somente conhecer a realidade, mas compreendê-la para transformá-la. Nesse sentido, nossa pesquisa é pautada numa perspectiva de totalidade no trato com o objeto numa dimensão dialética do conhecimento, vislumbrando a apreensão da realidade "para além da aparência e da causalidade dos fenômenos, em suas íntimas conexões internas, nas quais se autodeterminam" (CISNE, 2013, p. 37).

Para a realização desse estudo, utilizamos a abordagem qualitativa, tendo em vista que ela constitui uma relação dinâmica entre o mundo objetivo e a subjetividade do sujeito, formando um vínculo indissociável entre ambos que não pode ser traduzido em números.

Para a coleta dos dados, utilizamos como instrumento entrevistas com roteiro de perguntas semiestruturadas, que proporcionaram às entrevistadas falarem livremente a respeito do tema abordado. As cinco entrevistadas foram escolhidas aleatoriamente, obedecendo apenas ao critério de serem mães que estavam comprando brinquedos para seus filhos. As informações obtidas foram registradas por meio de gravação, com livre 


\section{heVistg eml paUtg}

\} A INFLUÊNCIA DA IDEOLOGIA PATRIARCAL - NASCIMENTO, A. C. O. \}

DOI: $10.12957 /$ REP.2016.25399

consentimento da entrevistada e assinatura de termo de consentimento livre esclarecido. Também utilizamos a pesquisa de imagem, na qual tivemos a oportunidade de fotografar departamentos de brinquedos infantis em algumas lojas (Americanas e Ri Happy) no West Shopping, localizado na cidade de Mossoró (RN). Dessa forma, o intuito era fazer uma análise comparativa de como os brinquedos estão organizados e divididos entre "brinquedos de menina e brinquedos de meninos". A análise desse conteúdo coletado na pesquisa nos possibilitou desvelar a ideologia subjacente que orienta as representações simbólicas e materiais expressas nos brinquedos.

Nesse estudo, procuramos analisar a expressão da ideologia patriarcal presente nos brinquedos infantis, que contribuem para a cristalização dos significados dominantes sobre os gêneros (feminino e masculino). Relacionamos, desse modo, a educação sexista com os brinquedos infantis, procurando mostrar que estes assumem, na socialização das crianças, um papel na reprodução das desigualdades nas relações sociais entre homens e mulheres. Fizemos, ainda, uma análise reflexiva das falas das entrevistadas, procurando mostrar a percepção destas acerca dos brinquedos, possibilitando desvendar, por meio dos discursos, as representações ideológicas que sustentam e afirmam facetas de uma cultura que separa homens e mulheres.

Por fim, fizemos uma análise interpretativa das imagens fotográficas coletadas na pesquisa de campo no intuito de mostrar as representações ideológicas e materiais presentes nos brinquedos infantis.

\section{Brinquedos infantis: a reprodução da ideologia patriarcal}

Os brinquedos disponibilizados e referenciados pelos adultos para as crianças são carregados de valores e preconceitos da cultura patriarcal. Por exemplo, os pais não permitem que seus filhos brinquem com brinquedos que não sejam "adequados" ao seu gênero e proíbem que os meninos brinquem com bonecas. Incorporam, assim, no cotidiano das crianças, os brinquedos que são destinados às meninas e aqueles destinados aos meninos, simbolizando os papéis hierárquicos entre homem e mulher, nos quais o masculino exerce a dominação sobre o feminino.

Nessa perspectiva, "desde a infância meninas e meninos recebem uma educação sexista" (CISNE, 2012, p. 160). Educação sexista é entendida, aqui, não apenas como aquela que diferencia homens e mulheres, mas que transforma diferenças em desigualdades sociais naturalizadas como algo definido biologicamente pelos sexos. No tocante aos brinquedos, estes são assimilados aos papéis conservadores de gênero estabelecidos pelo patriarcado, como "casinhas", jogos de panela, pratos, vassouras e bonecas similares a bebês reais, que expressam atividades reprodutivas, exercidas majoritariamente por mulheres. Já os brinquedos para meninos, por sua 


\section{ADVistg all paUtg}

\} A INFLUÊNCIA DA IDEOLOGIA PATRIARCAL - NASCIMENTO, A. C. O. \}

DOI: 10.12957/REP.2016.25399

vez, estão associados ao espaço público e não mantêm nenhuma relação com a paternidade, tampouco com as atividades domésticas. Nesse sentido, os brinquedos possuem uma carga ideológica patriarcal que assume, na socialização das crianças, um papel na reprodução das desigualdades nas relações sociais entre homens e mulheres.

\section{A educação sexista e os brinquedos infantis}

A desigualdade entre homens e mulheres, historicamente naturalizada nas relações sociais, encontra na educação sexista um suporte ideológico para sua reprodução cotidiana. Um fio condutor que possibilita a construção desse arranjo assimétrico entre os sexos reside nas explicações presumidas nos supostos determinantes biológicos. Ou melhor, na essência do que é considerado "feminino" e "masculino", que justifica e determina, à luz dos pensamentos sexistas, as "habilidades, qualidades, profissões, brinquedos ou espaço ditos de homem ou de mulher" (CISNE; BRETTAS, 2009, p. 61). Nesse sentido, utilizam-se dos determinantes biológicos, em seus aspectos físicos, psíquicos e comportamentais para justificar diferentes habilidades sociais, talentos e aptidões para impor um lugar de gênero na sociedade patriarcal-capitalista.

Questionar essa dicotomia que separa homens e mulheres, atribuindo papéis de acordo com o sexo, é perceber que as representações do "feminino e do masculino" não são determinadas biologicamente, mas pelas relações sociais. Nesse sentido, a educação de meninos e meninas tem um papel basilar na formação de valores e da cultura de gênero, construídos essencialmente por meio de instituições como família, igreja e escola. Como nos apontam Cisne e Brettas (2009, p. 61): "essas instituições alimentam um conjunto de valores conservadores sobre o comportamento de homens e mulheres - engendrado por meio da educação familiar, religiosa e escolar $[\ldots]^{\prime \prime}$.

É na família que se inicia a "domesticação" de meninas e meninos, e assim vão sendo desenhados os papéis do que é ser homem ou mulher, nomeados a partir de supostas diferenças biológicas. Assim, determinam um lugar como referência, na cultura hegemônica patriarcal, que cria relações materiais e representações simbólicas do lugar do homem e da mulher na sociedade, imputando posições que estes devem assumir de acordo com o sexo, afirmando a suposta "diferença natural" para estabelecer atribuições e deveres, consideradas "femininas ou masculinas". Nesses contornos, a família é a primeira instituição que nos coloca em contato com o mundo e, por meio dela, apreendemos a primeira forma de classificar e conceber o mundo. Conforme nos aponta Moreno (1999, p. 14): 
A partir do momento em que nascemos, começamos a receber essa influência social que condicionará nossa maneira de ver e de estar no mundo. Com a linguagem, aprendemos a primeira forma de dividir nosso universo em categorias. As palavras denominam as coisas, mas também fazem com que as agrupemos de uma determinada maneira em nosso pensamento.

Antes mesmo de as crianças nascerem, os pais já definem o que é "coisas de menina" e o que é "coisa de menino" por meio do enxoval, da seleção da cor do quarto e das roupas do bebê. Conforme a criança vai crescendo, "aprende com as primeiras palavras que existe uma 'mamãe' e um 'papai'; logo aprenderá que existem 'meninas' e 'meninos'" (MORENO, 1999, p. 14), concebendo como natural a sua essência "feminina" ou "masculina". De acordo com Chauí (1984, p. 134):

Ora, a família é organizada por relações de autoridade, de papéis distribuídos por sexo e idade, de deveres, obrigações e direitos, definidos tanto pelo sacramento do matrimônio quanto pelo casamento civil. É nesse contexto que a família realizará a repressão sexual [...]. Consolidam-se as imagens sexuais-sociais da mulher como mãe e do homem como pai. Consolidação que se realiza tanto pela repressão negativa (as proibições do sexo não-procriativo, o vício) quanto pela positiva. Nesta, a mulher é construída como um ser frágil, sensível e dependente, numa curiosa inversão dos valores desses atributos.

Em outros termos, a ideologia patriarcal estabelece e elege a família como uma âncora que sustenta o status quo das relações dominantes de sexo. Desde a infância, os pais ensinam às crianças como elas devem se comportar, o que é "certo" e "errado" e o que é "proibido" ou permitido". Quando os filhos não conseguem atender a tais critérios, eles se sentem culpados. Nesse sentido, para Chauí (1984, p. 9):

As proibições e permissões são interiorizadas pela consciência individual, graças a inúmeros procedimentos sociais (como a educação, por exemplo) e também expulsas para longe da consciência, quando transgredidas porque, neste caso, trazem sentimentos de dor, sofrimento e culpa que desejamos esquecer ou ocultar.

Desse modo, é no seio familiar que começam a se delinear os espaços que cada um pode ou não pode ocupar; na maioria das vezes, isso resulta em preconceitos distorcidos da realidade. Assim, vai sendo construído o que é considerado "coisa de menina ou coisa de menino", separando os brinquedos, as cores, as roupas, os espaços, dentre outros.

Nessa perspectiva, desde o nascimento (ou mesmo anteriormente a ele) meninas e meninos são cerceadas a assumirem papéis por meio das definições do "masculino e do feminino", como afirmam Cisne e Brettas (2009, p. 65): 


\section{ApVistg all paUtg}

\} A INFLUÊNCIA DA IDEOLOGIA PATRIARCAL - NASCIMENTO, A. C. O. \}

DOI: $10.12957 /$ REP.2016.25399

A construção do que devemos ser como homens ou mulheres iniciase anteriormente ao nosso nascimento. Isso se processa desde as mais simples definições do que é masculino ou feminino. A cor do enxoval e os brinquedos do quarto do bebê, escolhidos segundo o sexo, vêm acompanhados da definição das qualidades sociais e posturas que cada um(a) deve corresponder para ser bem aceito(a) socialmente e caracterizado(a) como 'normal'.

Como apontamos, é com a família que a criança tem um primeiro contato com as relações sociais, o que é determinante para as manifestações da primeira forma de consciência desses sujeitos. Isto porque é nessa instituição, a priori, que se internalizam valores, princípios e preconceitos da cultura patriarcal-capitalista, na qual são construídas as desigualdades entre homens e mulheres.

A escola, por sua vez, também "vem ratificar, desde a educação infantil, toda a construção simbólica do feminino e do masculino iniciada na família" (CISNE; BRETTAS, 2009, p. 67). Isso decorre do fato de que a escola é uma "fábrica" de formação dos indivíduos. É nesse espaço formal que se fortalece a construção de opiniões, comportamentos e posturas diante da própria identidade de gênero que é atribuída às crianças, fazendo com que elas façam uma leitura do mundo muitas vezes embebida na ideologia patriarcal dominante.

Nesse sentido, a escola, por meio de algumas práticas, legitima as possíveis diferenças atribuídas ao "feminino ou masculino", seja por meio da linguagem dos livros didáticos adotados e socializados para as crianças, seja pelas posturas e comportamentos diferenciados que alguns professores tomam com relação às crianças segundo o sexo, e/ou pelas atitudes dos próprios educadores no que diz respeito às singularidades e particularidades que podem reforçar ainda mais a desigualdade entre os sexos. É nesse sentido que as autoras Cisne e Brettas (2009, p. 68) referemse aos livros infantis escolares:

Assim, os contos e estórias infantis, e até mesmo livros de história, costumam apresentar os homens como heróis, fortes guerreiros, príncipes corajosos (brancos e ricos). São eles que libertam e salvam as 'frágeis' princesas [...]. Com isso, no máximo, as mulheres aparecem como 'musas inspiradoras' de homens, estes sim, sujeitos de sua própria história.

As literaturas infantis e os livros didáticos costumam trazer em seu contexto os significados e representações do feminino e do masculino, nos quais o homem vem como uma figura de guerreiro, forte e valente, e a mulher como frágil, delicada e dócil, que sempre fica à espera de seu príncipe, seu herói. Dessa forma, o homem aparece aí como personagem principal da história e a mulher como simples coadjuvante. Tudo só acontece pela postura do "guerreiro forte", que constrói a sua própria história de vida. Sobre os livros didáticos, afirma Louro (1997, p. 79): 
Os livros didáticos e paradidáticos têm sido objeto de várias investigações que neles examinam as representações dos gêneros, dos grupos étnicos, das classes sociais. Muitas dessas análises têm apontado para a concepção de dois mundos distintos (um mundo público masculino e um mundo doméstico feminino), ou para a indicação de atividades 'características' de homens e atividades de mulheres.

Nos livros didáticos é comum a apresentação com imagens de meninas brincando com sua casinha e cuidando da sua boneca-bebê; já os meninos aparecem com carrinhos, bolas e armas que reforçam sua liberdade, autonomia, força e independência. Com as meninas, os brinquedos considerados educativos e ofertados tanto na escola quanto pelos pais têm um caráter intimamente relacionado com as tarefas domésticas e atividades ou mesmo profissões extensivas a tais tarefas. Em outras palavras, os brinquedos estão associados à lógica patriarcal que rege a divisão sexual do trabalho e dos brinquedos a ela correlacionados. No caso, os brinquedos considerados de meninas têm um papel representativo na construção de sua identidade e posicionamento na sociedade, tendo em vista que são associados ao cuidado com os filhos e à atividade de dona de casa. Assim, estimulam as meninas a serem passivas e obedientes aos seus futuros maridos, de modo que elas são treinadas para se tornarem boas cuidadoras do lar por meio do cuidado com a cozinha, utensílios domésticos, troca de fraldas, mamadeiras e passeios com suas bonecas-bebês. Já com relação aos garotos, os brinquedos considerados de "meninos", como carrinhos, aviões, barquinhos, bonecos heróis e guerreiros, monstrinhos e "jogos eletrizantes" e de raciocínio lógico, são associados à criatividade, à aventura e ao desenvolvimento de habilidades.

Isso também é percebido nas disciplinas escolares, posto que é repassado ideologicamente que os meninos têm maior domínio com matérias envolvendo cálculos matemáticos. As meninas, por sua vez, teriam maiores habilidades com as disciplinas de ciências humanas. Esse pressuposto acaba sendo naturalizado e as crianças começam a absorver tais ideias, o que, muitas vezes, reflete na sua escolha profissional. Meninos "optam" mais por profissões que envolvem cálculos, como é o caso das engenharias, enquanto que as meninas acabam "optando", em sua grande maioria, por profissões vinculadas à reprodução social, como pedagogia, enfermagem e serviço social, cursos majoritariamente formados por muIheres.

A igreja também contribui com a produção e reprodução de princípios, (des)valores e preconceitos que reforçam a dominação e o controle das mulheres. Para tanto, utilizam ensinamentos de cunho conservador, preconceituoso e estigmatizante, que acabam, por vezes, estimulando o ódio e o desamor entre as pessoas, já que muitas não são aceitas por fugirem aos padrões e às doutrinas da igreja. 


\section{ADVistg all paUtg}

\} A INFLUÊNCIA DA IDEOLOGIA PATRIARCAL - NASCIMENTO, A. C. O.\}

DOI: $10.12957 /$ REP.2016.25399

Segundo Toledo (2001, p. 68) "[...] as religiões em geral comprem um papel decisivo na manutenção e propagação da ideia da mulher como 'sexo frágil' e 'ser inferior', ajudando a mantê-la subjugada e oprimida". O ensinamento religioso destinado às meninas acaba reforçando a submissão das mulheres, já que é dito que as mulheres devem ser submissas aos seus maridos, bem como devem respeitar as decisões do "cabeça da casa", sendo mulheres "valorosas" no cuidado com os filhos e com o marido. Aos meninos, é ensinado que eles são os provedores da família, tendo que assegurar o sustento da casa. Tudo isso acaba por acionar, na mente das "crianças", comportamentos e atitudes que remetem à distinção e desigualdades segundo o sexo, internalizando ideias de que homens e mulheres são diferentes dentro das relações sociais e, portanto, devem assumir papéis distintos.

Diante do exposto, faz-se necessário questionar a base de sustentação da desigualdade entre homens e mulheres. Esta respalda-se no sistema capitalista, o qual vem ao encontro desses estereótipos, reforçando, em prol de seus interesses, a desigualdade na divisão sexual do trabalho. Além disso, também contribui para a consolidação das diferenças entre homens e mulheres por meio da sua distinção no espaço de trabalho, nas diferenças salariais e na consequente inferiorização do trabalho feminino, que é relegado ao segundo plano.

Nessa perspectiva, o sistema capitalista se apropria da educação sexista para manter sua produção e reprodução por meio das desigualdades de gênero, afirmando a lógica da subalternização do trabalho feminino, aprofundando a dominação e exploração das mulheres. Desse modo, não basta somente repensar as "questões de gênero" na sociedade, mas também desvelar a raiz do problema, que reside na divisão entre classes e na divisão sexual do trabalho a ela associada. Por isso, é necessária a organização de lutas que venham de encontro aos interesses desse sistema de opressão a mulheres e homens, na busca por uma sociedade mais justa e igualitária, que garanta a emancipação das mulheres.

Para que isso seja possível, é preciso desconstruir socialmente os ditames da educação sexista, visando a ruptura com essa sociedade e a consolidação de uma nova sociedade pautada na igualdade e liberdade entre ambos os sexos. "Tem-se, portanto, que perceber a necessidade de ruptura com esta ordem para alcançar a emancipação" (CISNE; BRETTAS, 2009, p. 74).

\section{3. "Brinquedos de meninos e meninas": o que pensam as mães?}

\footnotetext{
"Que nada nos limite, que nada nos defina, que nada nos sujeite. Que a liberdade seja nossa própria substância." Simone de Beauvoir
}

Os brinquedos infantis assumem, na educação das crianças, uma fundamental importância, tendo em vista que, por meios deles, as crianças 


\section{ReVistg all pautg}

\} A INFLUÊNCIA DA IDEOLOGIA PATRIARCAL - NASCIMENTO, A. C. O.\}

DOI: 10.12957/REP.2016.25399

interiorizam o mundo dos adultos, constroem representações, significados, aprendem valores e princípios, acionados e referenciados pelos seus pais. Ao brincar, as crianças criam em suas mentes significados relacionados com sua família, apreendendo ensinamentos do mundo em que vivem, geralmente de maneira acrítica e naturalizante, como se as ideias que recebem sobre os brinquedos e a construção do seu gênero fossem inquestionáveis.

Os brinquedos disponibilizados pelos adultos às crianças possuem uma carga ideológica de significados de uma cultura que separa hierarquicamente homens e mulheres, atribuindo valores sociais dominantes. Ao eleger os brinquedos segundo o sexo, os pais acabam por acionar valores socialmente definidos como masculino e feminino. Assim, podemos entender os brinquedos como um sistema de significados tanto para aqueles que os difundem quanto para aqueles que os utilizam.

$\mathrm{Na}$ escolha dos brinquedos para seus filhos, geralmente os pais levam em consideração as supostas diferenças entre "coisa de menina e coisa de menino", atribuindo essa "separação" a características como fragilidade, delicadeza e docilidade, no caso das meninas; para os meninos, os brinquedos e brincadeiras são assimilados à força, coragem, aventura e criatividade. Além disso, "as manifestações espontâneas nas brincadeiras dos meninos costumam ser de caráter agressivo, como no caso de uma disputa de bola, no jogo de futebol" (MORENO, 1999, p. 27).

Desse modo, compreendemos que por trás dos brinquedos existe um código de linguagem do mundo heterossexual-capitalista-patriarcal, que separa meninos e meninas em dois polos antagônicos, segundo o sexo. Ou seja, é um depósito de ideologia e sistema de (des)valores dominantes, incumbidos de internalizar nas crianças significados e representações do feminino e do masculino. Reproduzem o sistema de poder hierárquico inscrito em papéis sociais, representados nos brinquedos para meninas em panelinhas, fogãozinho, boneca-bebê, entre outros, que são associados a características como delicadeza, romantismo, fragilidade, maternidade, trabalho doméstico e cuidado com os filhos e marido. Aos meninos, os brinquedos são representados em carrinhos e bonecos heróis, associados aos atributos masculinos, como ser forte, poderoso e aventureiro.

Nesse prisma, quando os pais se apropriam da ideologia patriarcal, acabam por internalizar na mente nas crianças, por meio dos brinquedos, essa suposta "diferença natural" entre homens e mulheres. Com isso, não apenas diferenciam as crianças segundo o sexo, mas estabelecem hierarquias e divisões entre ambos. De acordo com Moreno (1999, p. 32), nos limites restritos do sistema binário:

As meninas têm liberdade para ser cozinheiras, cabeleireiras, fadas madrinhas, mães que limpam seus filhos, enfermeiras, etc., e os meninos são livres para ser índios, ladrões de gado, bandidos, policiais, 'super-homens', tigres ferozes ou qualquer outro elemento da fauna agressiva.

EM PAUTA, Rio de Janeiro - 1 $^{\circ}$ Semestre de 2016 - n. 37, v. 14, p. 296 - 318 


\section{ADVistg all paUtg}

\} A INFLUÊNCIA DA IDEOLOGIA PATRIARCAL - NASCIMENTO, A. C. O. \}

DOI: 10.12957/REP.2016.25399

Assim, meninas e meninos são induzidos a seguir modelos, pretensamente considerado adequados ao seu gênero, sendo educados para aceitar as condições impostas como naturais. Tendo isso em vista, pretendemos, com a nossa pesquisa, compreender como se expressa a ideologia patriarcal na definição dos brinquedos. Para tanto, importa investigar e problematizar a construção social das relações de gênero na sociedade patriarcal-capitalista por meio da análise das falas das entrevistadas. Deve-se salientar que, a priori, pretendíamos entrevistar os pais; contudo, no dia da realização das entrevistas, encontramos apenas mães comprando brinquedos para os seus filhos. Isto se dá porque geralmente são as mulheres/ mães que costumam comprar brinquedos para as crianças, devido à naturalização das atividades e papéis que desempenham no âmbito familiar.

Nesse estudo, percorremos um caminho que nos proporcionou entrevistar mães que estavam comprando brinquedos para os seus filhos em algumas lojas no West Shopping, localizado na cidade de Mossoró (RN). Também tentamos entrevistar mães nas lojas do centro comercial da cidade; no entanto, foi inviável devido ao grande fluxo de pessoas nas lojas, assim como o tumulto, barulho e desinteresse das pessoas para serem entrevistadas.

Em face da limitação do objetivo desta pesquisa, não foi possível aprofundar algumas questões, como a dimensão da sexualidade, homofobia, consumo e indústria cultural, elementos determinantes para refinar a análise. Desse modo, tais indagações na verdade envolvem muitas variáveis e são muito complexas, portanto a problemática abordada aqui não se esgota nesse estudo.

Das cinco mães entrevistadas, todas tinham idade entre 34 a 47 anos. Todas residem em Mossoró, contudo três são naturais de outras cidades: Assu (RN), Patú $(R N)$ e Alcantil (PB). Em relação à religião, todas responderam que são católicas e, no que concerne à raça, três responderam que se consideram brancas e duas pardas. As entrevistadas possuem diferentes níveis de escolaridade, indo desde o ensino médio incompleto e completo, até o ensino superior completo e pós-graduação completa. No que diz respeito à profissão, variam entre dona de casa, secretária, auxiliar administrativa e professora com pós-doutorado.

Vale ressaltar que, para preservar a identidade das entrevistadas, atribuímos a elas nomes de bonecas, prezando pelo anonimato, que nos comprometemos a garantir no ato das entrevistas.

Diante das falas das entrevistadas, podemos perceber como é constituída essa teia de significados atribuídos aos brinquedos referentes às representações de gênero, desenhando, assim, um entrelaçado caminho que separa homens e mulheres, atribuindo o instituído lugar de gênero na sociedade capitalista-patriarcal. Nesse sentido, a partir dos dados obtidos nas entrevistas, pudemos perceber que os pais levam em consideração o sexo dos filhos na escolha dos brinquedos. Ao perguntar para uma das 


\section{ApVistg ell paltg}

\} A INFLUÊNCIA DA IDEOLOGIA PATRIARCAL - NASCIMENTO, A. C. O. \}

DOI: $10.12957 /$ REP.2016.25399

entrevistadas se ela percebe diferença entre brinquedo de menina e brinquedos de menino, obtemos a seguinte resposta:

Tem sim. Eu acho que menina tem muito mais feminilidade, algo mais delicado, algo mais cheio de pecinhas, de... não sei nem explicar certo a palavra. São mais delicadas. Meninos são mais radicais, né? E já são a maioria deles algo um pouco mais avançado, né? O meu, por exemplo, tem três anos e ele já escolhe esses brinquedos de transformers, de navios, alguma coisa que já é bem mais equipado. Uma menina de três anos, por exemplo... eu estou levando pra minha sobrinha, ela vê aquela coisinha bem mais delicada, bem menininha mesmo. (Polly).

Diante da fala da entrevistada, percebe-se que os pais levam em consideração, na escolha dos brinquedos, as supostas diferenças entre "coisa de menina e coisa de menino", atribuindo essa "separação" ao que consideram como características próprias de cada sexo. Na opinião da mãe entrevistada, os meninos desenvolvem o intelecto mais rapidamente que as meninas, posto que os brinquedos oferecidos para eles seriam mais "avançados" e "equipados". Para as meninas, os brinquedos seriam mais delicados devido à sua "feminilidade", "algo cheio de pecinhas", bem "menininha mesmo". Nessa perspectiva, percebe-se que os pais compram os brinquedos tipificados, tendo em vista que relacionam essas "diferenças" na essência do ser homem ou ser mulher. Como aponta a entrevistada: "[...] eu não daria uma boneca para o meu filho de jeito nenhum. Na escolha dos brinquedos eu considero o sexo sim" (Polly).

Os pais reproduzem nas crianças estereótipos de uma cultura assimétrica que institui a identidade do feminino e do masculino. É mister salientar que os pais expressam apreensões da ideologia patriarcal, que faz com que selecionem os brinquedos, já tipificados nas lojas, relacionandoos aos comportamentos e características que possam representar o sexo dos seus filhos. Assim, cremos que a "escolha" dos brinquedos pelas crianças guarda, muitas vezes, uma influência da educação sexista, que as induz ou, no mínimo, estimula, segundo o sexo, a "optar" por este ou aquele brinquedo. Quando as crianças, ao escolherem seus brinquedos, não correspondem ao que é esperado pela cultura patriarcal, muitas vezes são reprimidas.

Nas entrevistas, as mães falaram do modo como costumam reagir quando as crianças brincam com brinquedos tidos como do sexo oposto. Em geral, as mães não permitem que seus filhos brinquem com o que não consideram apropriado ou destinado para seu sexo. Ao perguntar se deixaria o filho brincar com bonecas ou outros brinquedos considerados de meninas, as mães responderam:

Deixo não, não porque eu fico brigando, dizendo que é coisa de menina, aí eu digo 'vá brincar com o velocipe [sic], com o boneco, 


\section{ApVistg all paUtg}

\} A INFLUÊNCIA DA IDEOLOGIA PATRIARCAL - NASCIMENTO, A. C. O. \}

DOI: $10.12957 /$ REP.2016.25399

com a bola', mas ele roda, roda pra mexer lá, pra brincar lá, mas eu não quero que ele brinque não. (Susi).

Não, se for um brinquedo unissex que não seja uma boneca, que não seja um carrinho da Barbie tudo bem, mas... (Polly).

Apenas uma das entrevistadas deu uma resposta diferente com relação à concepção e escolha dos brinquedos para os seus filhos:

[...] eu tenho uma filha de oito anos e tenho um menino de quatro anos, porém eles brincam muito juntos, entendeu? Tanto assim, juntam a casinha, cada um tem uma casinha, ele com os bonequinhos, ela com as bonecas, e vice-versa. Eu procuro sempre deixar eles interagirem, ter uma troca, mesmo que a sociedade, já é cultural, tem aquela coisa homem é de homem, mulher é de mulher. Eles brincam com brinquedos de meninas e vice-versa. Não direcionado pra boneca porque é assim, tem brinquedos de menina que não vejo problema nenhum os meninos brincarem e vice-versa. Um exemplo, bolas, se você for pegar uma bola tem personagens, por exemplo, da Barbie, mas é uma bola, então, qual é o problema do meu menino, da minha menina, do meu filho da minha filha... se eles estão brincando juntos, independente se a bola ser direcionada pra menino e pra menina, assim é o carro também. Como é que vou explicar, olha, né? O carro é cor de rosa pra mulher e verde ou outra cor pra homem. Não, independente disso, minha filha brinca de moto, motinha pequena que meu menino tem, por que? Porque na sociedade lá fora mulher anda de moto, então, pra não causar uma confusão na cabeça deles, tem coisa que a gente tem que tentar trabalhar desde pequeno pra não, sei lá, afetar psicologicamente o desenvolvimento deles. (July).

As demais entrevistadas que são mães de menino e menina assumem que não deixam seus filhos brincarem com bonecas; porém, as meninas até podem brincar com os brinquedos de meninos. Já os meninos, em sua maioria, são proibidos de brincar com bonecas e outros brinquedos considerados de meninas.

A menina brinca com todos os brinquedos deles, eu não proíbo, não proíbo termos assim... termos assim... por causa, assim... bola todos os dois lados jogam, já como velocipe [sic], todos os dois andam, né? Deixa eu ver... é! Tanto a bola, o velocipe [sic], bicicleta, já a boneca, a casinha de boneca, já, eu não gosto porque eu vejo assim, mais femininos, mais menininhas do que pra meninos. Na brincadeira todos podem brincar de tudo, menos se envolver brinquedos que eu considero femininos, tipo fogãozinho, panelinha, bonequinha, mas brincadeiras no geral não tem problema não [...]. (Susi).

Ela brinca, mas ele não brinca com brinquedos de meninas. Ela brinca com os brinquedos dele, mas ele não brinca com os brinquedos dela. (Barbie). 


\section{heVistg eml paUtg}

\} A INFLUÊNCIA DA IDEOLOGIA PATRIARCAL - NASCIMENTO, A. C. O. \}

DOI: $10.12957 /$ REP.2016.25399

Essas refrações da cultura patriarcal presentes nas falas acabam por atribuir sentidos na mente das crianças, influenciando no modo de agir, pensar e comportar-se em relação a sua própria sexualidade, postura e atitudes diante do sexo oposto. Além disso, os papéis sexuais ressignificados nos brinquedos e referenciados pelos pais influenciam, sobremaneira, no comportamento e atitudes das crianças, no momento em que elas são ensinadas a agirem de acordo com o sexo, pautado numa lógica essencialista que naturaliza desigualdades, estereótipos e hierarquias. Por exemplo, alguns pais demonstram, em seu discurso, que as meninas são delicadas, meigas e carinhosas. Os meninos são tidos como mais "diferentes", são ativos e competitivos. Tal comportamento sexista contribui para cristalizar a distinção de papéis e reforçar a suposta inferioridade da mulher e o poder do homem.

As falas indicam que os pais educam meninas e meninos de forma diferenciada, atribuindo significados e valores sexistas aos brinquedos que são disponibilizados para suas filhas e filhos. Na medida em que separam os brinquedos, tipificando-os como "de menina ou de menino", acabam estabelecendo uma relação assimétrica entre as crianças, contribuindo para que elas acreditem que são naturalmente diferentes em todas as esferas da vida e que devem assumir sua posição de homem ou de mulher, segundo os preceitos patriarcais. Como nos afirmam Cisne e Brettas (2009, p. 66) "[...] as meninas são educadas para serem frágeis, calmas, emotivas, submissas [...]. Os meninos, ao contrário, são educados para serem fortes, viris, dominadores, para ocuparem o espaço público-político [...]".

Notadamente, os brinquedos instituem significados para que as crianças reproduzam os papéis socialmente estabelecidos. Os brinquedos permitem que as crianças dramatizem as vivências do cotidiano, de forma que reproduzam e recriem situações da vida, acionando valores sociais da cultura hegemônica. Nesse sentido, os significados embutidos nos brinquedos, e que são referenciados pelos adultos e introjetados na mente e no corpo das crianças, atuam na construção de referências do ser homem ou mulher. Essa questão se torna explícita na fala de uma das entrevistas; quando perguntamos se ela acha que deve existir uma distinção entre brinquedo de menina e brinquedo de menino, ela expõe seu comportamento sexista:

Eu acho que sim, até pela questão da própria sexualidade, né? Eu acho assim... ainda vamos assim dizer, sou a favor da família tradicional. Eu acho que menina tem que brincar com brinquedos de menina, usando sua feminilidade, sua delicadeza. (Polly).

Na fala, a entrevistada deixa transparecer que, em sua opinião, os brinquedos podem influenciar na sexualidade, dando a entender que meninos que hoje brincam de bonecas podem ser os gays de amanhã. $\mathrm{O}$ 


\section{ADVistg all paUtg}

\} A INFLUÊNCIA DA IDEOLOGIA PATRIARCAL - NASCIMENTO, A. C. O. \}

DOI: 10.12957/REP.2016.25399

relato da entrevista ainda mostra um discurso preconceituoso e "cheio" de estereótipos de uma cultura heterocêntrica. Demonstra, ainda, a percepção da entrevistada acerca da figura da mulher, como sendo delicada, afirmando que deve existir a separação de brinquedos tidos como de meninas e de meninos.

Nas falas, as entrevistadas fazem uma relação dos brinquedos com a sexualidade. Quando é perguntado se elas permitem que seus filhos brinquem com bonecas ou outros brinquedos considerados de meninas, obtemos as seguintes respostas:

Eu não gostaria (risos). (Sandy).

E se ele pedisse?

Não, eu não dava não. (Sandy).

Eu não daria uma boneca para o meu filho de jeito nenhum. (Polly).

Dou não, mas eles querem brincar e eu não deixo. (Susi).

Os discursos que permeiam as falas das entrevistadas identificam que elas buscam manter as "diferenças", estabelecendo relações desiguais de poder e responsabilidades entre homens e mulheres. Revelam que as entrevistadas não gostariam que seus filhos (sexo masculino) brincassem com bonecas, casinhas e panelinhas, pois consideram como sendo "coisa de menina". As falas dão a entender que os meninos devem brincar com carrinhos, bolas, aviões, enfim, brinquedos que "representam" o ser masculino. Quando os meninos querem brincar com brinquedos tidos como de meninas são logo reprimidos e desapropriados de suas próprias vontades e desejos. Tudo isso acaba por reforçar a ideia de que homens não têm obrigação com as atividades domésticas, cuidado com os filhos e com a limpeza da casa, o que contribui com ideais machistas como o pensamento de que "lavar louça é coisa de mulher". Dessa forma, aos meninos são apresentados brinquedos que "estimulem" a criatividade, o domínio, a autonomia e a liberdade, tendo em vista que eles são educados para serem os dominadores e ocuparem o espaço público por meio da inserção no mundo da produção e participação nas decisões políticas.

Em outra fala podemos perceber a questão dos brinquedos vinculados aos papéis sociais baseados no sexo:

[...] os brinquedos de meninas, eu acho, eles estão muito ligados, geralmente para o cuidado, por exemplo, você vê muito bebezinho, muita bonequinha com roupinha pra você arrumar, como se você estivesse educando aquelas meninas para ser mãe, para ser dona de casa com pratinho, conjuntinho. E menino não, menino você já tem, por exemplo, uma máscara dessa de um herói, você tem armas, entendeu? É uma coisa assim, mais de luta para o menino se sentir um 
herói, e a menina não, é uma coisa assim, como se estivesse preparando ela pra ser uma dona de casa ou uma mamãe. Eu acho que tem diferença na concepção dos brinquedos. (Sandy).

A fala mostra que a mãe percebe diferenças na concepção dos brinquedos, os quais são assimilados aos papéis sociais assumidos por homens e mulheres, segundo o sexo, posto que ela faz uma relação entre o brinquedo que costuma ser destinado à menina ou ao menino com suas futuras atividades e/ou ocupações no espaço público e privado. No entanto, a entrevistada não faz nenhuma crítica ao sistema dicotômico instituído nos brinquedos. Em outra fala, ela acaba por concordar com essa diferença quando perguntamos se permite que seu filho brinque com brinquedos considerados de meninas:

Assim...específico de menina, por exemplo, essa aqui que estou dando pra minha sobrinha, é... eu não deixaria (risos). Se eu visse que é uma coisa de menina e ele me pedisse, por exemplo, ele me pediu o DVD do Cebolinha, mas, por exemplo, se ele me pedisse o DVD da Polly, eu não compraria. [...] Eu não acho interessante pra ele brincar com uma boneca (risos). (Sandy).

A visão de que determinado brinquedo é específico para menina ou menino advém de determinações sobre a suposta "existência" da natureza feminina ou masculina, encaixando na mente e corpo da criança modelos dicotômicos de comportamento e apreensões sociais de papéis e funções entendidas como sendo de homem ou de mulher. Dessa maneira, moldase as crianças para seguirem os ditames e paradigmas de uma ideia conservadora e patriarcal, acionando sentidos e comportamentos opostos. Nesse sentido, são repassadas ideologicamente para meninos e meninas representações de papéis, nos quais cabe à mulher o cuidado da casa e dos filhos, e aos homens o sustento da família por meio do trabalho fora de casa no mundo da produção. Isso faz com que as meninas associem as bonecas ao cuidado com as crianças e, portanto, apreendam que as bonecas são brinquedo de menina. Enquanto que os brinquedos para meninos, como carrinhos, são entendidos como poder de consumo e autonomia financeira.

Nesse prisma, quando as crianças se apropriam dos brinquedos disponibilizados e induzidos pelos pais, percebem que eles são considerados "certo" ou errado" para cada sexo. Daí surgem as contradições da ideologia patriarcal dominante, que constrói nas crianças posicionamentos que expressam o conservadorismo, preconceito e o desamor por aquilo que foge aos padrões pré-estabelecidos.

Quando a mãe ou o pai pró́bem o menino de brincar com bonecas, logo acionam na mente da criança que brincar com boneca é errado e não corresponde com seu sexo; ao verem algum garoto brincando com boneca, transformam-no em motivo de chacotas, do tipo "você virou bicha". 


\section{ADVistg all paUtg}

\} A INFLUÊNCIA DA IDEOLOGIA PATRIARCAL - NASCIMENTO, A. C. O. \}

DOI: 10.12957/REP.2016.25399

Tais comportamentos contribuem para que as crianças se tornem adultos preconceituosos e homofóbicos. Cremos que todas essas apreensões explícitas dos brinquedos são embebidas de alienação, o que faz com que os pais não percebam essas contradições, por reproduzir a ideologia patriarcal.

É dentro da instituição da família que vão sendo construídos os sujeitos sociais, moldados de acordo com os padrões pré-estabelecidos, implicando no modo de conceber o que é permito ou proibido no instituído lugar de gênero na sociedade. Nesse sentido, são geralmente os pais que "ensinam" aos filhos como estes devem se vestir, comportar, brincar e quais brinquedos são adequados ao sexo feminino ou masculino.

Ao perguntar para uma das entrevistadas se ela leva em consideração o sexo na escolha dos brinquedos, obtivemos a seguinte resposta: "É... Eu boto para escolher o lado deles" (Susi). Diante da fala, compreendemos que existem fronteiras e limites na vida cotidiana de meninos e meninas por meio de dois polos distintos, que fornecem distinções daquilo que é "apropriado" e identificado como sendo "coisa de homem" ou "coisa de mulher". Os pais ajustam os filhos às representações hegemônicas de cada gênero, orientando-os a se comportarem como sujeitos femininos e sujeitos masculinos. Dessa forma, as apreensões de gênero concebidas pelos pais e reproduzidas nas crianças acabam por contribuir na perpetuação da desigualdade social entre os gêneros, fortalecendo, assim, o poder hierárquico do mando e da obediência entre homens e mulheres.

Nesse contexto, a mãe demonstra preferências, comportamentos e atributos que configuram o seu posicionamento na concepção dos brinquedos associados ao sexo feminino ou masculino, relacionando a habilidades, aptidões e comportamentos tidos como de menina ou de menino. Ainda na fala das entrevistadas foi demonstrado que os pais delimitam não apenas os brinquedos em si, mas também os tipos de brincadeiras, impondo às crianças o que é "certo ou errado" segundo o sexo, como sendo "coisa de menina ou coisa de menino". Isto reafirma a divisão de gênero e traz problemas para as relações entre mulheres e homens.

Diante do exposto, entendemos que os brinquedos carregam consigo um conjunto de significados simbólicos e materiais que sustentam e afirmam a ideologia patriarcal. Instituem, a partir de sua representatividade na vida cotidiana das crianças, o mundo dividido em dois polos antagônicos, que conferem os papéis socialmente distintos entre o ser homem e o ser mulher.

Assim, acreditamos que as apreensões e sentidos que os pais dão aos brinquedos contribuem para a reprodução da ideologia patriarcal dominante e, portanto, para a manutenção e sustentação da estrutura de poder hierárquico que impõe à mulher a condição de inferioridade, afirmando o poder do homem em todas as esferas da vida em sociedade. 


\section{Fotos/imagens dos brinquedos: construção das supostas "diferenças" entre o ser homem e mulher}

Esse item nos convida a pensar os brinquedos como produtores de significados dos valores do sistema patriarcal na infância, posto que transmitem sentidos, definições e concepções relacionados ao gênero e internalizados nas crianças. Dessa maneira, apontam o lugar da criança no mundo dividido desigualmente entre homens e mulheres.

Por trás dos brinquedos existe um código de linguagem do mundo heterossexual-capitalista-patriarcal que separa meninos e meninas em dois polos antagônicos, segundo o sexo. Ou seja, é um depósito de ideologia e sistema de (des)valores dominantes, incumbidos de internalizar nas crianças significados e representações do feminino e do masculino, ressignificando o sistema de poder hierárquico inscrito em papéis sociais. Estes estão representados, por exemplo, nos brinquedos para meninas, tais quais panelinhas, fogãozinhos, bonecas-bebê, entre outros, que são associados a características como delicadeza, romantismo, fragilidade, maternidade, trabalho doméstico, cuidado com os filhos e marido. Já os brinquedos para meninos estão representados em carrinhos, bonecos heróis, associados aos atributos masculinos como ser forte, poderoso e aventureiro. Nesse sentido, com a nossa pesquisa de imagem pretendemos, a partir de uma análise comparativa dos brinquedos, desvelar os significados da ideologia patriarcal subjugados por um sistema dicotômico de (des)valores e preconceitos do sistema capitalista-patriarcal.

Nossa pesquisa de imagem foi realiza em algumas lojas no West Shopping em Mossoró (RN), no qual tivemos a oportunidade de fotografar os departamentos e seções de brinquedos e, a partir daí, perceber contradições na sua concepção.

\section{Figura 1. Fotografias de seções de brinquedos}
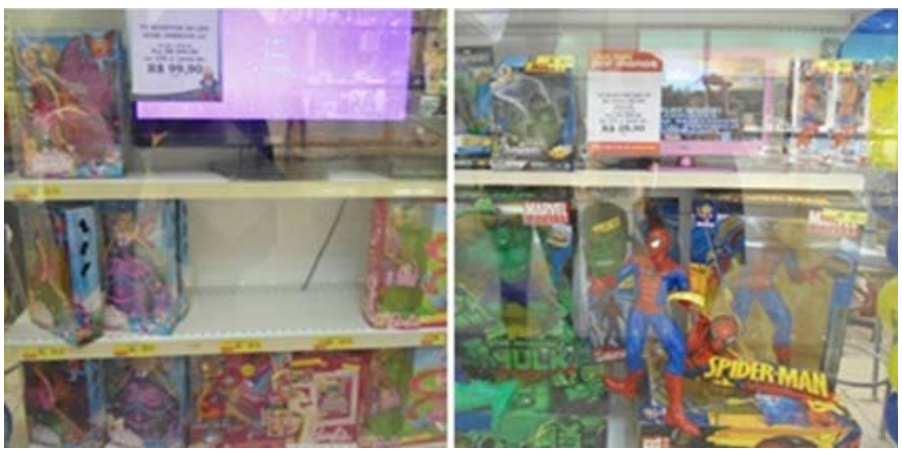

EM PAUTA, Rio de Janeiro - 1 $^{\circ}$ Semestre de 2016 - n. 37, v. 14, p. 296 - 318 


\section{ADVistg all paUtg}

\} A INFLUÊNCIA DA IDEOLOGIA PATRIARCAL - NASCIMENTO, A. C. O.\}

DOI: $10.12957 /$ REP.2016.25399

A Figura 1 demonstra como os departamentos de brinquedos são organizados e divididos em seções exclusivas para meninas e meninos, definidos, respectivamente, em tons de cor de rosa e azul, representando dois mundos distintos. O mundo masculino tem a ver com o espaço público, com a liberdade, autonomia e supremacia do poder do homem, tido como "superior". O mundo feminino, por outro lado, está ligado à domesticidade, à maternidade, à obrigação de cuidar dos filhos e ao zelo pelo bom andamento da casa.

Ainda na Figura1 temos a representação dos brinquedos considerados de meninas, tais quais bonecas-princesa, bonecas-bebê, jogos de panelinhas, pratinhos, cozinhas, kit de limpeza doméstica, entre outros ligados ao papel da mulher na sociedade capitalista-patriarcal. Por sua vez, os brinquedos considerados de meninos são representados por bonecosheróis, guerreiros com superpoderes, carrinhos, aviõezinhos, motinhas, trenzinhos, entre outros, que estão ligados ao mundo do puro lazer, diversão e aventura.

\section{Figura 2. Fotografias de laptops de meninas e meninos}

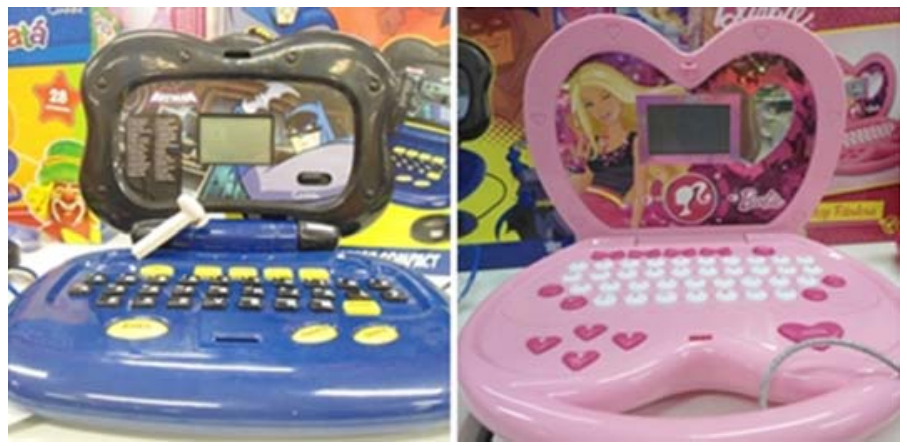

A Figura 2 mostra que brinquedos tidos como sendo de meninas vêm acompanhados de pecinhas com formato de coração, flor ou estrela, os quais estão intimamente relacionados com características consideradas femininas, como romantismo, delicadeza, feminilidade, docilidade. Os brinquedos tidos como de meninos vêm com pecinhas que lembram ferramentas e instrumento tecnológicos, ou melhor, são réplicas bem próximas do mundo real dos adultos masculinos.

O designer e os brinquedos em si são ricos de significações sexistas e representações de papéis entendidos como próprios de homens ou de mulheres, como, por exemplo, os kits de salão de beleza, bonecas bailarinas ou kit de limpeza doméstica, que estão relacionadas com profissões majoritariamente femininas, tais quais cabeleira, bailarina e empregada doméstica. Já as significações dos brinquedos de meninos estão em outra dimensão, 


\section{heVistg eml paUtg}

\} A INFLUÊNCIA DA IDEOLOGIA PATRIARCAL - NASCIMENTO, A. C. O. \}

DOI: $10.12957 / R E P .2016 .25399$

por exemplo, carrinhos, trenzinhos, miniaturas de postos de gasolina estão relacionados com o transporte e com o poder financeiro e de consumo dos homens, bem como os brinquedos espaciais e as ferramentas tecnológicas estão relacionados com a ciência, entendida como espaço exclusivo dos homens.

As estruturas de gênero descritas nos brinquedos são bastante diferentes para homens e mulheres, como podemos observar na Figura 3 e Figura 4. Vejamos:

\section{Figura 3. Fotografias de brinquedos para menina}
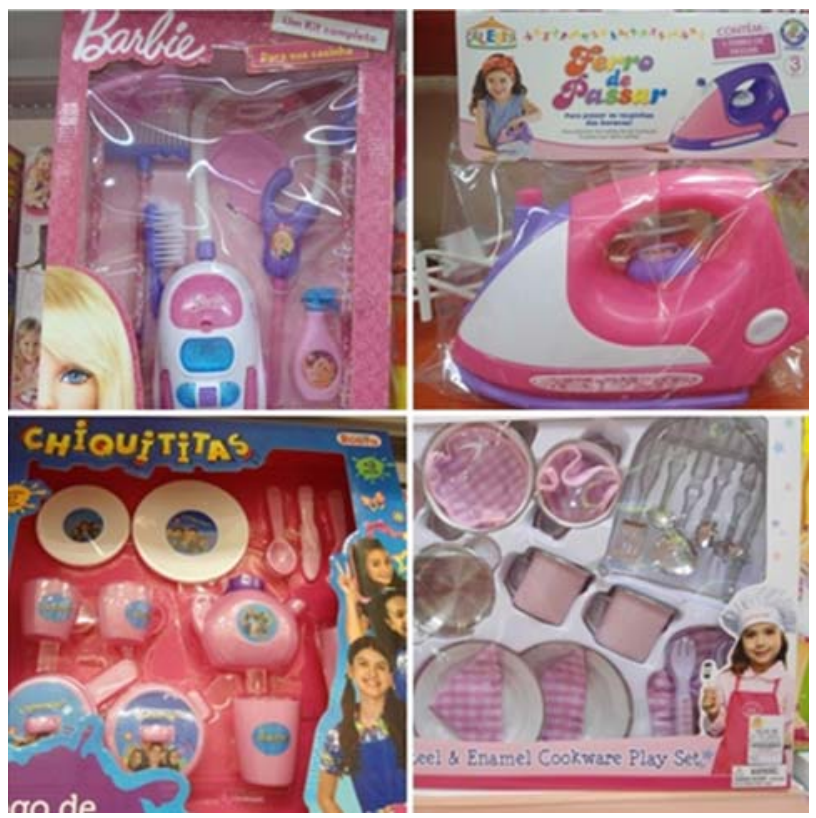

As diferenças nos brinquedos tidos como de meninas são percebidas em várias dimensões; primeiro, nas cores em tons de rosa, relacionado à atmosfera de romance, feminilidade, tranquilidade e inocência infantil; segundo, nos tipos de brinquedos, como ferro de passar roupas, aspirador de pó, vassouras, panelinhas e pratinhos, que são símbolos do espaço doméstico, tido como feminino. Dessa forma, no sistema patriarcal, o cuidado com a casa e os filhos é considerado como obrigação e papel da mulher.

Compreende-se, portanto, que o patriarcado se corporifica em bases materiais e simbólicas presentes nos brinquedos. É um sistema de dominação e exploração, concebendo a figura da mulher como um ser inferior, definida na qualidade de mãe e dona de casa. 


\section{ADVistg all paUtg}

\} A INFLUÊNCIA DA IDEOLOGIA PATRIARCAL - NASCIMENTO, A. C. O. \}

DOI: $10.12957 /$ REP.2016.25399

\section{Figura 4. Fotografia de brinquedos para meninos}
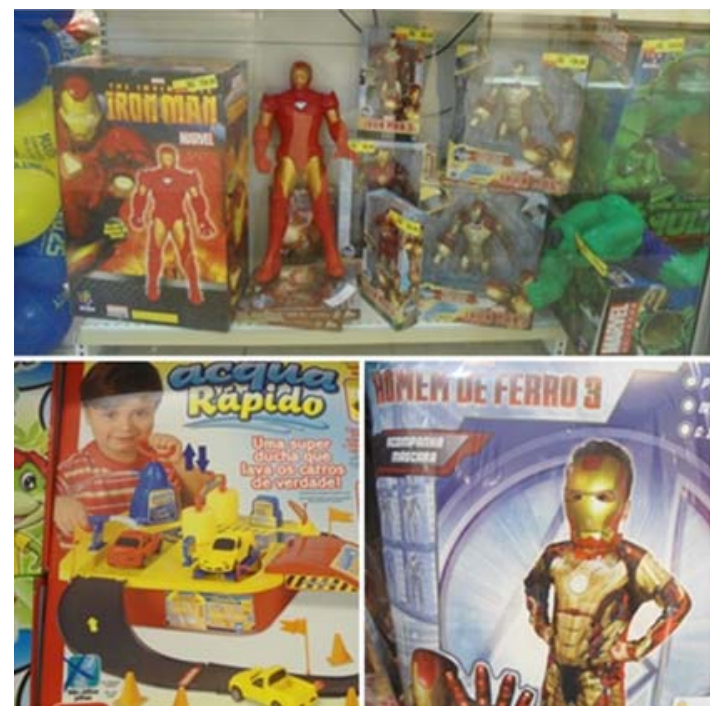

Na Figura 4 observa-se que a estrutura e as cores dos brinquedos são totalmente distintos dos brinquedos das meninas, posto que a maioria dos brinquedos de meninos são representados em tons de azul, preto, cinza, amarelo e verde, tons que representam perigo, mistério, aventura e poder. No tocante aos brinquedos em si, estes são bonecos, heróis, guerreiros, monstrinhos, carrinhos e aviões, relacionando-se à ideia de ser homem na sociedade, ser forte, poderoso, guerreiro, um verdadeiro "homem de ferro".

\section{Figura 5. Fotografia de boneca-bebê e carrinhos com lava-rápido equipado}
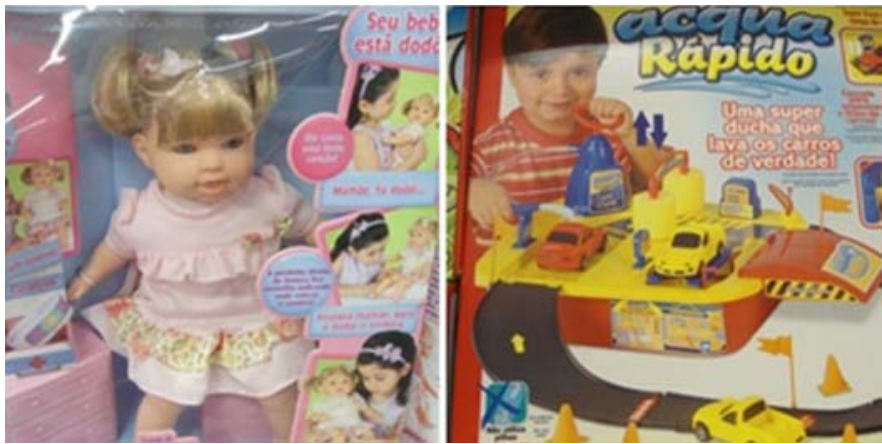

Como podemos observar na Figura 5, os brinquedos para meninas estão relacionados com o espaço da casa, atividades domésticas e a própria 


\section{heVistg eml paUtg}

\} A INFLUÊNCIA DA IDEOLOGIA PATRIARCAL - NASCIMENTO, A. C. O. \}

DOI: $10.12957 /$ REP.2016.25399

questão da maternidade. Isto nos levar a crer que os brinquedos transmitem significados relacionados ao papel da mulher na sociedade capitalista-patriarcal. Além disso, vemos que a paternidade está basicamente ausente do mundo dos brinquedos.

Diante disto, percebemos que os brinquedos não são simplesmente sinônimo de brincar, mas também representam ideologias de uma cultura que separa homens e mulheres, atribuindo-lhes papéis sociais determinados segundo o sexo. Intervêm diretamente no modo de pensar, agir e comportarse das crianças, diante dos padrões e valores do sistema patriarcal.

Em face ao exposto, ressaltamos que os brinquedos estão intimamente relacionados com os interesses do sistema capitalista-patriarcal, que cuidou de absorver em si um conjunto de significados ligados aos papéis, comportamentos, aptidões e habilidades entre os gêneros. Para corresponder a tais interesses, o capital se utiliza de uma relação hierárquica e subalternizada entre os gêneros. Confere, assim, às mulheres um baixo prestígio social ao submetê-las a um trabalho mais precarizado e desvalorizado, o que contribui sobremaneira com o aumento das taxas de lucros por meio da superexploração da força de trabalho feminina.

Engana-se quem pensa que os brinquedos são simplesmente objetos inócuos que não trazem nenhuma contribuição para o modo de ser, agir e comportar-se das crianças. Desde cedo as crianças são cerceadas e convencidas a seguirem padrões comportamentais que representam as ideias e valores dominantes. É pensando nisso que o sistema patriarcal-capitalista agirá, partindo da indústria de brinquedos que recria significados sexistas e papéis de gênero, marcados pelas relações desiguais.

Essa divisão sexual dos brinquedos implica, por sua vez, no fortalecimento da cultura que institui a divisão sexual do trabalho, relação material central para a sustentação do patriarcado. Desse modo, o sistema patriarcal-capitalista se apropria dos brinquedos por meio de processos ideológicos, a fim de manter a divisão entre os sexos. O intuito é justificar as "diferenças" construídas socialmente como sendo relacionadas ao biológico, numa tentativa de ocultar a superexploração sobre o trabalho e atividades desenvolvidas por mulheres, tanto na esfera privada quanto na esfera pública.

Essa relação dicotômica entre os sexos é construída desde a infância por meio da educação sexista, que encontra forte expressão nos brinquedos associados aos papéis hierárquicos e desiguais entre esses sujeitos. Nesse prisma, quando os pais se apropriam da ideologia patriarcal acabam por internalizar na mente nas crianças, por meio dos brinquedos, essa suposta "diferença natural" entre homens e mulheres. Com isso, não apenas diferenciam as crianças segundo o sexo, mas estabelecem hierarquias e divisões entre ambos os sexos. 


\section{ADVistg all paUtg}

\} A INFLUÊNCIA DA IDEOLOGIA PATRIARCAL - NASCIMENTO, A. C. O. \}

DOI: $10.12957 /$ REP.2016.25399

\section{Considerações finais}

A apreensão do processo de construção social das relações de gênero é complexa, pois envolve um sistema de dominação-exploração. Este atua em conjunto na perpetuação de uma estrutura de poder no sentido de mascarar a realidade, apresentando os fenômenos como naturais e tomando os aspectos biológicos do "macho" e da "fêmea" para justificar uma suposta diferença entre o feminino e masculino. Dessa forma, consolida-se o essencialismo biológico, o que contribui para a opressão das muIheres e a primazia do homem.

Diante da análise das entrevistas, pudemos perceber que os pais levam em consideração o sexo dos filhos na escolha dos brinquedos. Ou seja, levam em consideração as supostas diferenças entre "coisa de menina e coisa de menino", atribuindo essa "separação" a características como fragilidade, delicadeza e docilidade para as meninas; para os meninos, os brinquedos são assimilados à força, coragem, aventura, criatividade, entre outras.

Nesse sentido, percebemos que as mães entrevistadas, com exceção de uma, educam os filhos para as representações hegemônicas de cada gênero, orientando-os a se comportarem como sujeitos femininos e sujeitos masculinos, segundo a ideologia patriarcal.

A partir deste estudo obtivemos alguns resultados. Os departamentos de brinquedos são organizados e divididos em seções exclusivas para meninas e para meninos, definidos em tons de cor de rosa e azul, representando dois mundos distintos. Ao analisar as figuras, percebemos que os brinquedos considerados de meninas estão associados ao espaço privado da casa, ao cuidado com os filhos e com o marido. Já os brinquedos tidos como de meninos estão relacionados ao ser homem na sociedade, ser forte, poderoso, guerreiro, um verdadeiro "homem de ferro".

Afirmamos a necessidade de se construir uma educação libertária e emancipada, que forme o ser humano numa dimensão crítica, voltada para a defesa da igualdade e da liberdade, numa busca constante de desvelar as relações sociais desiguais de gênero na sociedade capitalista, baseada na educação não sexista. Nesse sentido, cremos na importância da educação libertária, na qual os seres humanos sejam capazes de respeitar as diferenças, sem transformá-las em desigualdades.

Diante do exposto, acreditamos que é possível educar as crianças numa perspectiva igualitária, na qual todos possam interagir e brincar juntos, sem nenhuma barreira que os separem segundo sexo, tampouco raça ou classe. Que seja permitido recriar nos brinquedos vivências igualitárias, libertárias e democráticas entre meninos e meninas, construindo relações humanizadas, que respeitem o outro em suas diferenças e semelhanças, aceitando-o como realmente é, em seus desejos e vontades, repudiando tudo o que os reprima, que os negue, que os afaste da expressão do seu verdadeiro "eu". 
heVistg all pautg

\} A INFLUÊNCIA DA IDEOLOGIA PATRIARCAL - NASCIMENTO, A. C. O.\}

DOI: 10.12957/REP.2016.25399

\section{Referências}

CISNE, M. Feminismo, luta de classes e consciência militante feminista no Brasil. Tese (Doutorado em Serviço Social) Universidade do Estado do Rio de Janeiro. Rio de Janeiro: Uerj. 2013.

. Gênero, divisão sexual do trabalho e Serviço Social. São Paulo: Outras Expressões. 2012.

CISNE, M.; BRETTAS, T. Que homens e mulheres educamos? In: TAVARES, J. M. C.; MARINHO, Z. (Org.). Educação, saberes e práticas no oeste potiguar. Fortaleza: UFC. 2009.

CHAUÍ, M. de S. Repressão sexual: essa nossa (des)conhecida. São Paulo: Brasiliense. 1984.

LOURO, G. L. Gênero, sexualidade e educação: uma perspectiva pósestruturalista. Petrópolis: Vozes. 1997.

MORENO, M. Como se ensina a ser menina: o sexismo na escola. São Paulo: Moderna; Campinas: Editora da Universidade Estadual de Campinas. 1999.

TOLEDO, C. Mulheres: o gênero nos une, a classe nos divide. São Paulo: Editora Xamã. 2001.

Recebido em 26 de fevereiro de 2015.

Aprovado para publicação em 26 de junho de 2016.

DOI: 10.12957/rep.2016.25399

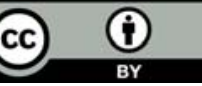

A Revista Em Pauta: Teoria Social e Realidade Contemporânea está licenciada com uma Licença Creative Commons Atribuição 4.0 Internacional. 